\title{
Experimental evidence in support of transannular interactions in diketones
}

\author{
Kata Mlinarić-Majerski, ${ }^{a, *}$ Marijana Vinković, ${ }^{a}$ Danko Škare, ${ }^{a}$ and Alan P. Marchand ${ }^{\text {b }}$ \\ ${ }^{a}$ Department of Organic Chemistry and Biochemistry, Rudjer Bošković Institute, \\ P. O. Box 180, 10002 Zagreb, Croatia \\ ${ }^{b}$ Department of Chemistry, University of North Texas, Denton, Texas 76203-5070 US \\ E-mail: majerski@,rudjer.irb.hr
}

Dedicated to Professor D. E. Sunko on the occasion of his $80^{\text {th }}$ birthday

(received 19 Nov 01; accepted 03 Jun 02; published on the web 11 Jun 02)

\begin{abstract}
The acid catalyzed condensation of polycyclic ketones 1-4 with thiadithiols was carried out. The reaction of ketone $\mathbf{1}$ with thiadithiols 5 and $\mathbf{6}$ afforded corresponding crown ethers $\mathbf{7}$ and 8 respectively. However all diketones 2-4 reacted with 5 or $\mathbf{6}$ to give corresponding ethylene dithioketals 9-13. To the best of our knowledge, these results provide the first example of chemical evidence for the operation of transannular interactions in rigid polycarbocyclic systems.
\end{abstract}

Keywords: Diketones, transannular interactions, thiadithiols, dithioketals

\section{Introduction}

Since the electron delocalization through homoconjugation in terms of direct ("through-bond") and indirect ("through-space") interactions has been described by Hoffmann, ${ }^{1}$ this phenomenon has been extensively investigated. Several papers have appeared that compare changes in ${ }^{13} \mathrm{C}$ $\mathrm{nmr}$ shift values of the $\mathrm{sp}^{2}$ carbon atoms in difunctional systems with those of the corresponding monofunctional congeners. ${ }^{2}$ Transannular orbital interactions have been detected by photoelectron ${ }^{3,4}$ and electron transmission spectroscopy. ${ }^{5}$ The origins of transannular interactions in diketones and methyleneketones also have been studied by ab initio $\mathrm{MO}^{6}$ and semiempirical electron density analysis. ${ }^{7}$

Herein we report remarkable difference between the reactions of thiadiethanethiols with monoketone $\mathbf{1}$ and with diketones $\mathbf{2}, \mathbf{3}$ and $\mathbf{4}$, and we present experimental evidence for transannular interactions in diketones $\mathbf{3}$ and $\mathbf{4}$. 


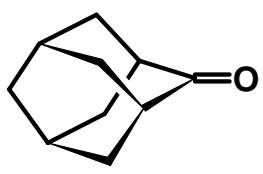

1

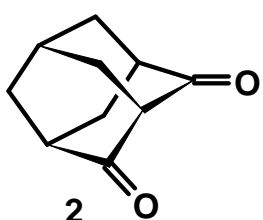

2

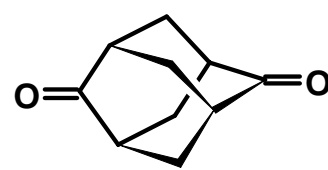

3

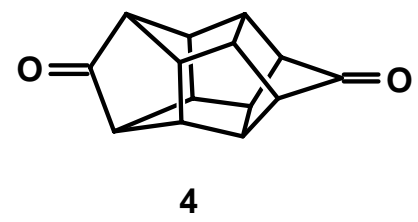

\section{Results and Discussion}

Recently, it was shown that acid catalyzed condensation of 2,2'-thiadiethanethiol with carbonyl compounds or equivalents thereof could lead to thiacrown ethers that contain thioacetal units. ${ }^{8}$ From our interest in the synthesis of adamantane-containing thiacrown ethers, ${ }^{9}$ we have studied the acid catalyzed condensation of adamantanones 1-3 with 2,2'-thiadiethanethiol (5) and 3,6dithiaoctane-1,8-dithiol (6). The required starting compounds $\mathbf{1},{ }^{10} \mathbf{2},{ }^{11} \mathbf{3},{ }^{12}$ and $\mathbf{4},{ }^{13}$ could be prepared by using straightforward literature procedures.

Acid catalyzed condensation of $\mathbf{1}$ with $\mathbf{5}$ or $\mathbf{6}$ gave spiro-adamantane thiacrown ethers $\mathbf{7}$ and 8, respectively, in a good yield (Scheme 1). However the same reactions performed with diketones $\mathbf{2}$ or $\mathbf{3}$, instead of corresponding crown ethers, afforded corresponding ethylene dithioketals 9-12 (Scheme 2). Ethylene dithioketals 9 and $\mathbf{1 0}$ as well as $\mathbf{1 1}$ and 12, were separated by preparative TLC. Structures of all new compounds were characterized via analysis of their respective IR, proton NMR, and carbon-13 NMR spectra (see the Experimental Section) and by elemental microanalysis. Structural assignments were confirmed by comparison with NMR spectra of authentic samples prepared by using standard methods via reaction of ethanedithiol with diketones 2 and $\mathbf{3}^{14}$

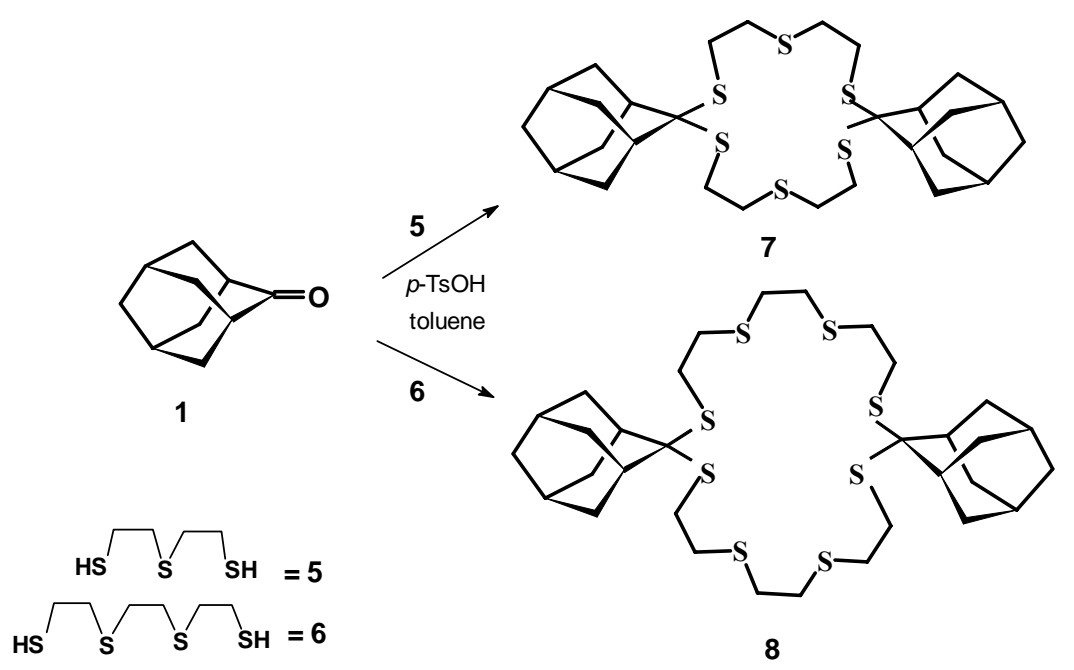

Scheme 1 
When reaction was performed by using a 1:2 molar ratio of diketone and dithiol the corresponding bis(ethylene dithioketals) 9 and 11 were obtained (Table 1). The unusual course of the reactions observed when diketones $\mathbf{2}$ and $\mathbf{3}$ were employed as substrates could be explained in terms of electron delocalization through homoconjugation. ${ }^{2,6}$ Clearly, when two carbonyl groups are present (as in substrates $\mathbf{2}$ and $\mathbf{3}$ ), one $\mathrm{C}=\mathrm{O}$ group exerts a profound influence upon the reactivity of the other toward nucleophilic reagents.

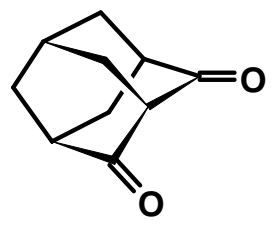

2

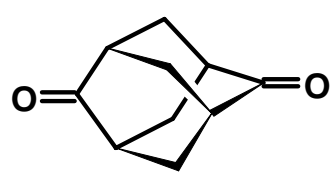

3

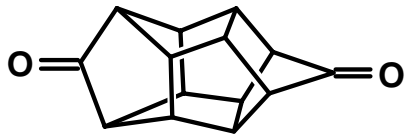

4
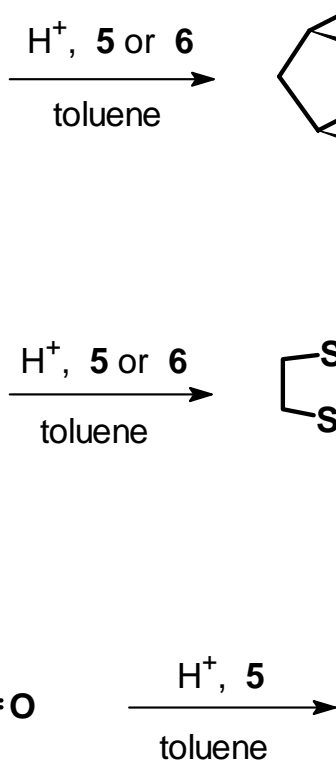

toluene

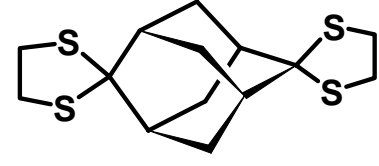

11

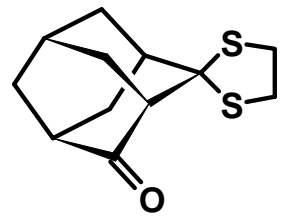

10

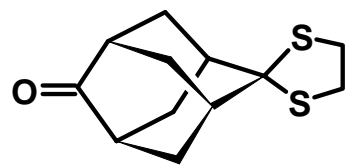

12

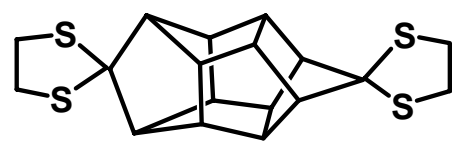

13

\section{Scheme 2}

Table 1. Reactions of diketones 2, 3, and $\mathbf{4}$ with dithiols 5 and $\mathbf{6}$ in toluene catalyzed by p-TsOH

\begin{tabular}{cccc}
\hline Diketones & Dithiols & $\begin{array}{c}\text { Ratio of } \\
\text { diketone: dithiol }\end{array}$ & ${\text { Products }(\%)^{\mathrm{a}}}$ \\
\hline $\mathbf{2}^{\mathrm{b}}$ & $\mathbf{5}$ & $1: 1$ & $\mathbf{9}(12)+\mathbf{1 0}(45)$ \\
$\mathbf{2}$ & $\mathbf{5}$ & $1: 2$ & $\mathbf{9}(89)$ \\
$\mathbf{2}$ & $\mathbf{6}$ & $1: 2$ & $\mathbf{9}(85)$ \\
$\mathbf{3}^{\mathrm{b}}$ & $\mathbf{5}$ & $1: 1$ & $\mathbf{1 1}(23)+\mathbf{1 2}(48)$ \\
$\mathbf{3}$ & $\mathbf{5}$ & $1: 2$ & $\mathbf{1 1}(58)$ \\
$\mathbf{3}$ & $\mathbf{6}$ & $1: 2$ & $\mathbf{1 1}(25)$ \\
$\mathbf{4}$ & $\mathbf{5}$ & $1: 2$ & $\mathbf{1 3}(89)$ \\
\hline
\end{tabular}

${ }^{\mathrm{a}}$ Isolated yield.

${ }^{\mathrm{b}}$ Small amount of starting diketone was isolated. 
In order to obtain additional insight into the nature of transannular electronic effects that originate from localized carbonyl groups, the corresponding acid catalyzed condensation of diketone 4 with dithiol 5 was studied. Again, the bis(ethylene dithioketal) 13, was isolated in $89 \%$ of yield as a sole product (Table 1). It should be noted that both diketones, 3 and $\mathbf{4}$, possess $D_{2 \mathrm{~d}}$ symmetry. The $\mathrm{C}=\mathrm{O}$ groups in diketone $\mathbf{3}$ and $\mathbf{4}$ are separated by four and five $\sigma$-bonds, respectively. It was calculated ${ }^{6}$ that $\mathrm{sp}^{2}$ carbon atoms in $\mathbf{3}$ are separated by a transannular distance of $3.463 \AA$; the corresponding distance in 4 is considerably greater (i.e., $5.265 \AA$ ). However, the calculations clearly indicated that electron density is greater around the carbonyl carbon atoms in $\mathbf{3}$ and $\mathbf{4} v i s$-à-vis that in the corresponding monoketone reference compounds. ${ }^{6}$

On the basis of the results shown in Scheme 1 and 2 and in Table 1, it is apparent that protonated ketone is the reacting electrophile when the reaction is performed under acidic conditions. ${ }^{15}$ Under these conditions two reaction mechanisms may operate (Scheme 3). With monoketone 1, path a appears to be more likely and tertiary carbocation is formed leading to the formation of crown ether 7 .

However, when a second carbonyl group is present in the substrate (as, e.g., in 3), the transannular dipolar effect of this $\mathrm{C}=\mathrm{O}$ group is expected to destabilize an incipient carbocationic center, ${ }^{16}$ thereby favoring path $\mathbf{b}$ and formation of thionium ion, which decomposes to 12. Reaction of $\mathbf{1 2}$ with the second mole of dithiol $\mathbf{5}$ leads to the formation of $\mathbf{1 1 .}$

To the best of our knowledge, the foregoing results provide the first example of chemical evidence for the operation of transannular interactions in rigid polycarbocyclic systems.

\section{Experimental Section}

General Procedures. ${ }^{1} \mathrm{H}$ and ${ }^{13} \mathrm{C}$ NMR spectra were obtained by using Varian Gemini 300 nuclear magnetic resonance spectrometer. The assignment of the NMR signals was done by a combination of 2D NMR techniques $\left({ }^{1} \mathrm{H}-{ }^{1} \mathrm{H}\right.$ COSY and ${ }^{1} \mathrm{H}_{-}{ }^{13} \mathrm{C}$ HETCOR $)$. IR spectra were recorded on a Perkin-Elmer M-297 spectrophotometer and MS on Extrel FTMS 2001 spectrometer. The purity of adamantyl compounds was determined by GLC analysis carried out on a Varian 3300 gas chromatograph equipped with a DB-210 capillary column. Melting points were determined on Kofler apparatus and are uncorrected. Elemental analyses were performed at Central Analytical Laboratory, IRB, Zagreb. Unless stated otherwise, reagent grade solvents were employed.

\section{General procedure to synthesize crown ethers 7 and 8}

$p$-Toluenesulfonic acid (catalytic amount) was added with stirring to refluxing toluene $(1 \mathrm{~L})$. To the resulting hot solution was added dropwise with stirring a solution of 2-adamantanone (1) and thiadithiol 5 (or 6) in toluene ( $1 \mathrm{~L}$ ) during 2 days. After the addition had been completed, the reaction mixture was refluxed for 8 days. The reaction mixture was allowed to cool gradually to ambient temperature and then was concentrated in vacuo. Diethyl ether $(80 \mathrm{~mL})$ was added to the 
residue, and the resulting suspension was filtered through a sintered glass funnel. The filtrate was concentrated in vacuo, thereby affording recovered (unreacted) 1. The dark brown residue was purified via column chromatography on silica gel by using a $50 \% \mathrm{CH}_{2} \mathrm{Cl}_{2}$-pentane/100\% $\mathrm{CH}_{2} \mathrm{Cl}_{2}$ gradient elution scheme.

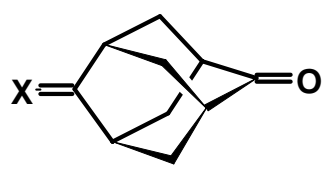

$1 \mathrm{X}=2 \mathrm{H}$

$3 X=0$
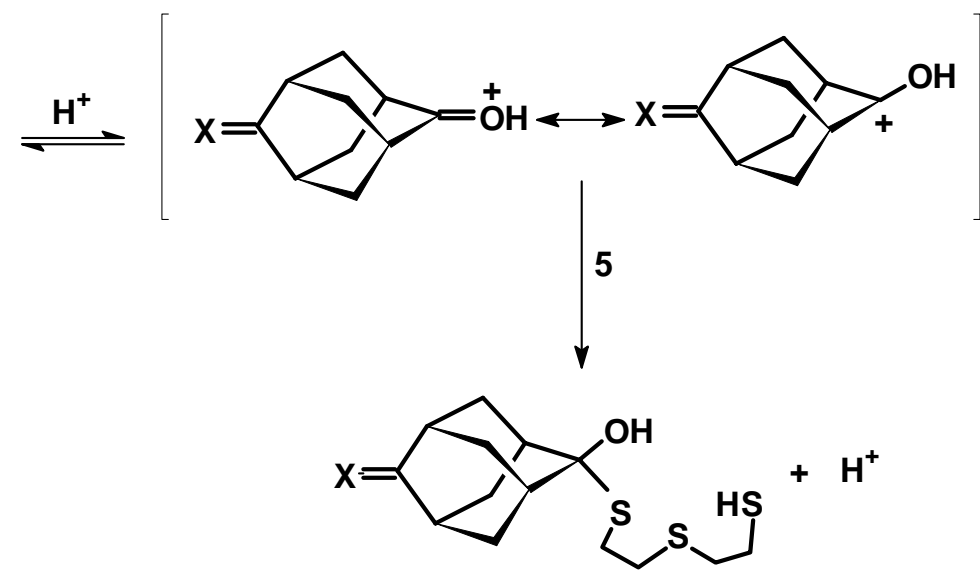

b $-\mathrm{H}_{2} \mathrm{O}$
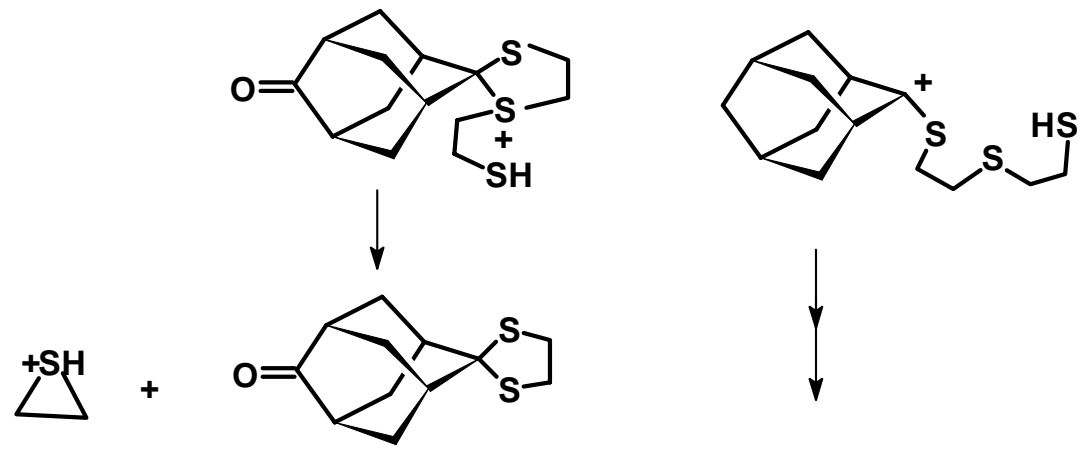

12

7

5

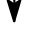

11

\section{Scheme 3}

2,10-Bis-spiro(2-adamantylidene)-1,3,6,9,11,14-hexathiacyclohexadecane (7). Using general procedure compound $7(1.7 \mathrm{~g}, 81 \%$, based upon recovered 1) was obtained as a colorless microcrystalline solid by the reaction of 1 (3.00 g, $20 \mathrm{mmol})$ with 5 (3.09 g, $20 \mathrm{mmol})$. This material was washed with hexane to afford analytically pure 7: mp 260-263 ${ }^{\circ} \mathrm{C}$. ${ }^{1} \mathrm{H}$ NMR $\left(\mathrm{CDCl}_{3}\right) \delta 1.63\left(A \mathrm{~B}, J_{A B}=12.4 \mathrm{~Hz}, 8 \mathrm{H}\right), 1.71$ (br. s, 4H), 1.87 (br. s, 4H), 1.92 (br. s, 4H), 2.51 $\left(\mathrm{AB}, J_{A B}=12.4 \mathrm{~Hz}, 8 \mathrm{H}\right), 2.69-2.96(\mathrm{~m}, 16 \mathrm{H}) ;{ }^{13} \mathrm{C} \mathrm{NMR}\left(\mathrm{CDCl}_{3}\right) \oint 27.06(\mathrm{~d}, 4 \mathrm{C}), 28.57(\mathrm{t}, 4 \mathrm{C})$, 
$30.51(\mathrm{t}, 4 \mathrm{C}), 33.23(\mathrm{t}, 8 \mathrm{C}), 35.87(\mathrm{~d}, 4 \mathrm{C}), 38.78(\mathrm{t}, 2 \mathrm{C}), 71.78(\mathrm{~s}, 2 \mathrm{C})$; IR (KBr) 2930 (s), 2855 (m), $1470(\mathrm{~m}), 1450(\mathrm{~m}), 1440(\mathrm{~m}), 1095(\mathrm{~m}), 810(\mathrm{~m}), 795(\mathrm{~m}) \mathrm{cm}^{-1}$; HRMS (CI) Calcd. for $\mathrm{C}_{28} \mathrm{H}_{44} \mathrm{~S}_{6}:[\mathrm{M}+\mathrm{H}]^{+} m / z$ 573.184558. Found: $m / z$ 573.182809.

Anal. Calcd. for $\mathrm{C}_{28} \mathrm{H}_{44} \mathrm{~S}_{6}$ : C, 58.68; H, 7.74. Found: C, 58.63; H, 7.76.

2,13-Bis-spiro(2-adamantylidene)-1,3,6,9,12,14,17,20-octathiacyclodocosane (8). Using general procedure compound $\mathbf{8}(1.8 \mathrm{~g}, 39 \%$ based upon recovered 1) was obtained as a low melting solid by the reaction of $1(3.00 \mathrm{~g}, 20 \mathrm{mmol})$ with $\mathbf{6}(4.30 \mathrm{~g}, 20 \mathrm{mmol}) .{ }^{1} \mathrm{H} \mathrm{NMR}\left(\mathrm{CDCl}_{3}\right)$ $\delta 1.52\left(\mathrm{AB}, \mathrm{J}_{\mathrm{AB}}=12.4 \mathrm{~Hz}, 8 \mathrm{H}\right), 1.71$ (br. s, $\left.4 \mathrm{H}\right), 1.84-1.94(\mathrm{~m}, 8 \mathrm{H}), 2.50\left(\mathrm{AB}, \mathrm{J}_{\mathrm{AB}}=12.4 \mathrm{~Hz}\right.$, $8 \mathrm{H}), 2.65-2.95(\mathrm{~m}, 24 \mathrm{H}) ;{ }^{13} \mathrm{C} \mathrm{NMR}\left(\mathrm{CDCl}_{3}\right) \delta 26.85(\mathrm{~d}, 4 \mathrm{C}), 28.86(\mathrm{t}, 4 \mathrm{C}), 31.57(\mathrm{t}, 4 \mathrm{C}), 31.92$ (t, 4C), 33.15 (t, 8C), 35.96 (d, 4C), 38.55 (t, 2C), 71.81 (s, 2C); IR (KBr-film) 2910 (s), 2855 (m), 1460 (m), 1450 (m), 1425 (m), 1100 (m), 960 (m), 810 (m), 795 (m) cm ${ }^{-1}$; HRMS Calcd. for $\mathrm{C}_{32} \mathrm{H}_{52} \mathrm{~S}_{8}:[\mathrm{M}+\mathrm{H}]^{+} m / z$ 693.191302. Found: $m / z$ 693.192759.

General procedure employed for acid catalyzed condensation of diketones 2 and 3 with thiadithioles 5 or 6

Solution of diketone 2 (or 3) and thiadithiols 5 (or 6) in toluene (100 mL) was added drop by drop with stirring into refluxing toluene $(100 \mathrm{~mL})$ which contained catalytic amount of $\mathrm{p}-\mathrm{TsOH}$. Reaction mixture was stirred for ten days and the course of the reaction was monitored via thin layer chromatographic analysis $\left(\mathrm{SiO}_{2}\right.$ stationary phase, eluent $\left.\mathrm{CH}_{2} \mathrm{Cl}_{2}\right)$. After the reaction was completed, toluene was distilled off, and crude brown oil was dried on rotary evaporator. The mixtures of products, mono(ethylene dithioketals) and bis(ethylene dithioketals) thereby obtained were separated by preparative thin layer chromatography on silicagel eluting with dichloromethane.

Adamantane-2,4-dione 2,4-bis(ethylene dithioketal) (9, $0.102 \mathrm{~g}, 12 \%)$ and adamantan-2,4-dione 4-ethylene dithioketal (10, $0.288 \mathrm{~g}, 45 \%)$ were obtained as a colorless microcrystalline solid by condensation of diketone $2(0.436 \mathrm{~g}, 2.66 \mathrm{mmol})$ and thiadithiol 5 (0.410 g, $2.66 \mathrm{mmol})$.

9. Colorless shiny needles, mp: $102-105{ }^{\circ} \mathrm{C} .{ }^{1} \mathrm{H}$ NMR $\left(\mathrm{CDCl}_{3}\right) \delta 1.57-1.71(\mathrm{~m}, 3 \mathrm{H}), 1.74-1.92(\mathrm{~m}$, $3 \mathrm{H}), 2.16-2.35(\mathrm{~m}, 5 \mathrm{H}), 2.41-2.54(\mathrm{~m}, 1 \mathrm{H}), 3.01-3.24(\mathrm{~m}, 8 \mathrm{H}) ;{ }^{13} \mathrm{C} \mathrm{NMR}\left(\mathrm{CDCl}_{3}\right) \delta 24.32(\mathrm{~d}$, 1C), 35.29 (t, 1C), $36.18(\mathrm{t}, 2 \mathrm{C}), 37.49$ (t, 2C), 38.59 (t, 1C), $39.26(\mathrm{t}, 2 \mathrm{C}), 40.39$ (d, 2C), 52.63 (d, 1C), 78.48 (s, 2C); IR (KBr): 2920 (s), 2860 (s), 1455 (m), 1280 (m), 1175 (m), 1035 (m), $970(\mathrm{~m}), 810(\mathrm{~m}) \mathrm{cm}^{-1}$. Anal. Calcd. for $\mathrm{C}_{14} \mathrm{H}_{20} \mathrm{~S}_{4}$ : C, 53.11; H, 6.37; S, 40.52. Found: C, 53.18; H, 6.32; S, 40.50 .

10. Colorless needles, mp: 56-59 ${ }^{\circ} \mathrm{C} .{ }^{1} \mathrm{H}$ NMR $\left(\mathrm{CDCl}_{3}\right) \delta 1.85-2.09(\mathrm{~m}, 5 \mathrm{H}), 2.11-2.24(\mathrm{~m}, 3 \mathrm{H})$, 2.38-2.54 (m, 3H), 2.68 (br. s, 1H), 3.24 (br. s, 4H); ${ }^{13} \mathrm{C} \mathrm{NMR}\left(\mathrm{CDCl}_{3}\right) \delta 25.66$ (d), 36.09 (t), $36.53(\mathrm{t}), 38.38(\mathrm{t}), 38.66(\mathrm{t}), 39.18(\mathrm{t}), 39.41(\mathrm{t}), 40.66(\mathrm{~d}), 44.95(\mathrm{~d}), 60.84(\mathrm{~d}), 76.33(\mathrm{~s})$, 214.18 (s); IR (KBr): 2920 (s), 2860 (s), 1720 (s), 1450 (m), 1280 (m), 1080 (m), 1030 (m), 970 (m) $\mathrm{cm}^{-1}$.Anal. Calcd. for $\mathrm{C}_{12} \mathrm{H}_{16} \mathrm{OS}_{2}$ : C, 59.96; H, 6.71. Found: C, 59.88; H, 6.94.

Adamantane-2,6-dione 2,6-bis(ethylene dithioketal) (11, 0.116 g, 23\%) and adamantan-2,6-dione 6-ethylene dithioketal $(\mathbf{1 2}, 0.172 \mathrm{~g}, 48 \%)$ were obtained as a colorless microcrystalline solid by condensation of diketone $3(0.248 \mathrm{~g}, 1.66 \mathrm{mmol})$ and thiadithiol 5 (0.262 g, $1.66 \mathrm{mmol})$. 
11. Colorless shiny needles, mp: $132-134{ }^{\circ} \mathrm{C} .{ }^{1} \mathrm{H}$ NMR $\left(\mathrm{CDCl}_{3}\right) \delta 2.00(\mathrm{~s}, 4 \mathrm{H}), 2.21(\mathrm{~s}, 8 \mathrm{H}), 3.24$ $(\mathrm{s}, 8 \mathrm{H}) ;{ }^{13} \mathrm{C} \mathrm{NMR}\left(\mathrm{CDCl}_{3}\right) \delta 35.67(\mathrm{t}, 4 \mathrm{C}), 38.38$ (t, 4C), 39.87 (d, 4C), 77.10 (s, 2C); IR (KBr): 2920 (s), 2865 (s), 1460 (m), 1285 (m), 1100 (m), 970 (m), 825 (m) cm ${ }^{-1}$; HRMS Calcd. for $\mathrm{C}_{14} \mathrm{H}_{20} \mathrm{~S}_{4}:\left[\mathrm{M}^{+}\right] \mathrm{m} / z$ 316.044239. Found: $m / z$ 316.044169.

Anal. Calcd. for $\mathrm{C}_{14} \mathrm{H}_{20} \mathrm{~S}_{4}$ : C, 53.11; H, 6.37; S, 40.52. Found: C, 53.12; H, 6.31; S, 40.30.

12. Colorless needles, mp 102-104 ${ }^{\circ} \mathrm{C}$. ${ }^{1} \mathrm{H}$ NMR $\delta$ 1.92-2.07 (m, 4H), 2.2 (br. s, 2H), 2.39-2.53 $(\mathrm{m}, 6 \mathrm{H}), 3.32(\mathrm{~s}, 4 \mathrm{H}) ;{ }^{13} \mathrm{C} \mathrm{NMR} \delta 37.56(\mathrm{t}, 4 \mathrm{C}), 38.95(\mathrm{t}, 2 \mathrm{C}), 41.00(\mathrm{~d}, 2 \mathrm{C}), 44.27(\mathrm{~d}, 2 \mathrm{C}), 75.52$ (s, 1C), 216.41 (s, 1C); IR (KBr): 2920 (s), 2865 (s), 1720 (s), 1425 (m), 1310 (m), 1210 (m), $1030(\mathrm{~m}), 820(\mathrm{~m}) \mathrm{cm}^{-1}$; HRMS for $\mathrm{C}_{12} \mathrm{H}_{16} \mathrm{OS}_{2}:\left[\mathrm{M}^{+}\right]: \mathrm{m} / z$ 240.063710. Found: $\mathrm{m} / z$ 240,061938. Anal. Calcd. for $\mathrm{C}_{12} \mathrm{H}_{16} \mathrm{OS}_{2}$ : C, 59.96; H, 6.71; S, 26.68. Found: C, 60.03; H, 6.45; S, 26.71.

Heptacyclo[6.6.0.0 $\left.0^{2,6} \cdot 0^{3,13} \cdot 0^{4,11} \cdot 0^{5,9} \cdot 0^{10,14}\right]$ tetradecane-7,12-dione 7,12-bis(ethylene dithioketal) (13). Solution of heptacyclo[6.6.0.0. $\left.0^{2,6} \cdot 0^{3,13} \cdot 0^{4,11} \cdot 0^{5,9} \cdot 0^{10,14}\right]$ tetradecane-7,12-dione $(4,0.050 \mathrm{~g}, 0.23 \mathrm{mmol})$ and thiadithiol 5 (0.072 g, 0.46 mmole) in toluene $(16 \mathrm{~mL})$ was added with stirring into refluxing toluene $(7.5 \mathrm{~mL})$ which contained a catalytic amount of $\mathrm{p}$-toluensulfonic acid and the mixture was stirred for 24 hours. The course of the reaction was monitored via thin layer chromatographic analysis $\left(\mathrm{SiO}_{2}\right.$ stationary phase, $2 \% \mathrm{MeOH}-\mathrm{CH}_{2} \mathrm{Cl}_{2}$ eluent). After the reaction had been completed, the reaction mixture was concentrated to remove toluene, and the residue was evaporated to dryness in vacuo (rotary evaporator). The material thereby obtained was purified via column chromatography on silica gel by eluting with $50 \%$ pentane- $\mathrm{CH}_{2} \mathrm{Cl}_{2}$. Pure $13(0.075 \mathrm{~g}, 87 \%)$ was thereby obtained as a colorless microcrystalline solid: mp 138-140 ${ }^{\circ} \mathrm{C} .{ }^{1} \mathrm{H}$ NMR $\left(\mathrm{CDCl}_{3}\right) \delta 2.57$ (br. s, 4H), 2.78 (br. s, 8H), 3.23 (s, 8H); ${ }^{13} \mathrm{C} \mathrm{NMR}\left(\mathrm{CDCl}_{3}\right) \delta 38.75$ (t, 4C), 53.47 (d, 8C), 61.64 (d, 4C), 83.38 (s, 2C); IR (KBr): 2964 (s), 2919 (s), 1420 (m), 1280 (m), 985 (m), 835 (m) cm . $^{-1}$ Anal. Calcd. for $\mathrm{C}_{18} \mathrm{H}_{20} \mathrm{~S}_{4}$ : C, 59.29; H, 5.53; S, 35.18. Found: C, 59.12; H, 5.66; S, 34.96.

\section{Acknowledgments}

We thank the Ministry of Science and Technology of the Republic of Croatia (Grant P00980702 to K. M-M.). A. P. M. thanks the Robert A. Welch Foundation (Grant B-0963), the Texas Advanced Technology Program (Grant 003659-0206-1999), and the U.S. Department of Energy (Grant DE-FG07-98ER14936) for financial support.

\section{References}

1. (a) Hoffmann, R. Acc. Chem. Res. 1971, 4, 1. (b) Hoffmann, R.; Imamura, A.; Hehre, W. J. J. Am. Chem. Soc. 1968, 90, 1499.

2. (a) Majerski, Z.; Vinković, V.; Meić, Z. Org. Magn. Reson. 1981, 17, 169. (b) Senda, Y.; Ishiyama, J.; Imaizumi, S. J. Chem. Soc., Perkin Trans. 2 1981, 90. (c) Duddeck, H. Tetrahedron 1983, 39, 1365. (d) Bishop, R. Aust. J. Chem. 1984, 37, 319. (e) Bishop, R.; 
Lee, G.-H. Aust. J. Chem. 1987, 40, 249. (f) Chow, T. J.; Wu, T.-K.; Shih, H.-J. J. Chem. Soc., Chem. Commun. 1989, 490. (g) Mlinarić-Majerski, K.; Vinković, V.; Chyall, L. J.; Gassman, P. G. Magn. Res. Chem. 1993, 31, 903. (h) Gurst, J. E.; Schubert, E. M.; Boiadjiev, S. E.; Lightner, D. A. Tetrahedron 1993, 49, 9191.

3. (a) Albert, B.; Elsässer, D.; Martin, H.-D.; Mayer, B.; Chow, T. J.; Marchand, A. P.; Ren, C.-T.; Paddon-Row, M. N. Chem. Ber. 1991, 124, 2871. (b) Doerner, T.; Gleiter, R.; Robbins, T. A.; Chayangkoon, P.; Lightner, D. A. J. Am. Chem. Soc. 1992, 114, 3235.

4. (a) Paddon-Row, M. N. Acc. Chem. Res. 1982, 15, 245. (b) Paddon-Row, M. N.; Jordan, K. D. In Modern Models of Bonding and Delocalization; Liebman, J. F.; Greenberg, A. Eds; Verlag Chemie: Weinheim; 1988; pp 115-194; (c) Gleiter, R.; Schäfer, W. Acc. Chem. Res. 1990, 23, 369.

5. Balaji, V.; Jordan, K. D.; Gleiter, R.; Jähne, G.; Müller, G. J. Am. Chem. Soc. 1985, 107, 7321. (b) Balaji, V.; Ng, L.; Jordan, K. D.; Paddon-Row, M. N.; Patney, H. K. J. Am. Chem. Soc. 1987, 109, 6957.

6. Paddon-Row, M. N. Tetrahedron 1994, 50, 10813.

7. Chow, T. J.; Li, L.-P. Tetrahedron 1999, 55, 6067.

8. Xianming, H.; Kellogg, R. M.; Bolhuis, v. F. J. Chem. Soc., Perkin Trans. 1 1994, 707.

9. Vinković, M. Ph. D. Thesis, University of Zagreb, 2002.

10. Geluk, H. W.; Keizer, V. G. Org. Synth. 1988, Coll. Vol. 6, 48.

11. Faulkner, D.; McKervey, M. A. J. Chem. Soc. (C) 1971, 3906.

12. (a) Geluk, H. W. Synthesis 1972, 374. (b) Lavrova, L. N.; Klimova, N. V.; Shmar'yan, M. I.; Skoldinov, A. P. Zh. Org. Chim. 1976, 12, 2369.

13. Marchand, A. P.; Earlywine, A. D. J. Org. Chem. 1984, 49, 1660.

14. Sondheimer, F.; Rosenthal, D. J. Am. Chem. Soc. 1958, 80, 3995.

15. The control experiments showed that thiadithioles $\mathbf{5}$ and $\mathbf{6}$ are stable in the applied reaction conditions.

16. Smith, M. B.; March, J. Advanced Organic Chemistry; $5^{\text {th }}$ Edn, John Wiley \& Sons: New York, 2001; pp 389-462. 